\title{
Descrever a LGP em contexto bilingue: o género
}

\author{
Isabel Sofia Calvário Correia ${ }^{1}$
}

\section{Resumo}

Este trabalho baseia-se numa investigação realizada no Pós-doutoramento em Linguística da Língua Gestual Portuguesa (LGP) na Universidade de Coimbra. Pretendemos ilustrar a materialização de género em LGP e sua aplicação didática no ensino bilingue, mais concretamente no ensino do português como segunda língua, através de sugestões práticas elaboradas por nós. Baseamo-nos nos trabalhos de Quadros (2004); Wendy Sandler e Lillo Martin (2006); Tanya Felipe (2006); Figueiredo, Silva e Sell (2009); Barbosa e Rafael (2014); Amaral (1994).

Palavras-Chave: Língua Gestual Portuguesa; Género; Ensino Bilingue de surdos

\section{Abstract}

This essay results of a research done in the Post-Phd in Portuguese Sign Language Linguistics at the University of Coimbra. We intend to describe how gender is expressed in Portuguese Sign Language and how it can be

${ }^{1}$ Instituto Politécnico de Coimbra. Escola Superior de Educação (IPC-ESEC). Coimbra. Portugal.icorreia@esec.pt

Este artigo está escrito em Português de Portugal por forma a preservar a identidade linguística do país de onde é a Língua Gestual Portuguesa. 
tought in bilingual schools for the deaf, mainly concerning portuguese as a second language teaching. We consider the works done by Quadros (2004); Wendy Sandler \& Lillo Martin (2006) Tanya Felipe (2006), Figueiredo Silva \& Sell (2009), Barbosa \& Rafael (2014), AMARAL (1994).

Key-words: Portuguese Sign Language; Gender; Bilingual teaching for the deaf

Ao contrário do que sucede na investigação linguística do português, em que os processos de marcação de género têm vindo a ser amplamente discutidos desde, pelo menos, os anos setenta até aos nossos dias, os trabalhos sobre o género nas línguas gestuais são praticamente inexistentes. De facto, este campo apenas merece uma singela nota de rodapé em obras de referência como a de Lillo Martin e Wendy Sandler (2006) ou então é estudado a par de processos de formação de palavras, como são exemplos os estudos da Língua Brasileira de Sinais (LIBRAS) de Tanya Felipe (2006), Sofia Figueiredo (2004), entre outros. Na Língua Gestual Portuguesa o silêncio é ainda maior, havendo apenas algumas considerações pontuais (CORREIA, 2009) ou de âmbito didático (AMARAL e COUTINHO,1994).

Não temos resposta para essa escassez de reflexão sobre a marcação de género. Talvez outras unidades gramaticais e respetivas categorizações, porque têm concretizações específicas nas Línguas Gestuais, como os classificadores ou a iconicidade, suscitem o interesse dos investigadores. Porém, este deserto que se verifica relativamente ao género não é, de todo, sinónimo que o contraste não exista ou seja residual, como procuraremos mostrar nas secções seguintes. 


\section{O Género nas Línguas Gestuais : um território inseguro}

Como dissemos anteriormente, quase nada é dito sobre o género nas línguas gestuais, mesmo naquelas que são mais estudadas como a American Sign Language (ASL) ou a LIBRAS (Língua Brasileira de Sinais). Assim, Wendy Sandler e Lillo Martin, no capítulo da sua obra dedicado à morfologia flexional, começam por dizer que "the sign language inflectional morphology of most interess is found on predicates" (p. 23), e afirmam, em nota de pé de página: "There is no gender or case marking on nouns, except for possessive pronouns" (SANDLER e LILLO MARTIN, 2006, p. 23, nota 1, sublinhado nosso).

Tendo em conta que nesta obra as autoras utilizam diversas línguas gestuais para exemplificar os universais linguísticos e diversas propriedades das línguas, nomeadamente a ASL, a Língua Gestual Italiana, a LIBRAS, a Língua Gestual Israelita, entre outras, a afirmação das duas investigadoras parece-nos um pouco surpreendente. De facto, mesmo na ASL, existe contraste masculino/feminino. Na sua maioria, como adiante veremos, esse contraste faz-se por variação lexical, mas também há gestos que possuem marcação de género por outro processo, que abaixo descreveremos, como é o caso do gesto SISTER ${ }^{2}$; algo idêntico se passa na LIBRAS, como veremos, na Língua Gestual Italiana e na grande maioria das línguas gestuais ${ }^{3}$.

Os estudos em torno da LIBRAS relativos a essa questão são mais pormenorizados. Assim, Silva e Sell (2009), estudando os processos de composição morfológica e morfossintática ${ }^{4}$ na LIBRAS referem-se à marcação de género como composição aparente, afirmando o seguinte:

2 Veja-se o ASL Dictionary disponível em < http://www.handspeak.com/word/search/ index.php?id=1977> Consultado em: 21 de junho de 2015.

3 Para os exemplos de várias línguas gestuais, utilizamos o Spread the Sign, um dicionário multilingue, disponível em <http://www.spreadthesign.com>. O exemplo gestuado por um informante que aparece no anexo a este trabalho e que não figura no spreadthesign participou de livre vontade neste estudo e consentiu a publicação da sua imagem. Usamos maiúsculas quando nos referimos a exemplos de uma língua gestual.

4 Usamos a terminologia expressa no Dicionário Terminológico (DT). 
Os nomes na libras não possuem marcação morfológica de gênero. Quando é necessário esclarecer qual é o sexo do referente numa situação de enunciação, uma das maneiras de fazê-lo nos substantivos de libras é a combinação dos sinais independentes, HOMEM ou MULHER, com o sinal de base, como mostram os exemplos abaixo:

\section{(11) a. HOMEM^CRIANÇA [menino]}

b. MULHER^CRIANÇA [menina $]^{5}$

Em (11), ao sinal CRIANÇA acrescentou-se em primeira posição o sinal HOMEM ou MULHER, esclarecendo assim qual é o sexo do referente. Este recurso parece ser muito comum na língua. (...) Estes sinais apresentam distribuição de nome na língua, já que podem assumir a função sintática de sujeito e de objeto nas sentenças. Observe-se, no entanto, que não convém chamar a este processo "flexão de gênero", já que não se trata de um verdadeiro processo flexional - ele não apresenta certas propriedades que já Mattoso Camara Jr. (1970) isola como propriedades do sistema flexional, como a obrigatoriedade, a regularidade e o fato de desencadear concordância. $\mathrm{Na}$ verdade, ele se parece mais com o expediente lexical, que consiste na aposição das palavras macho e fêmea em português que usamos exatamente quando queremos esclarecer o sexo de um referente no caso de o nome não admitir flexão de gênero, como em cobra macho ou jacaré fêmea.

Por outro lado, tampouco é possível tomar este tipo de combinação entre sinais como verdadeira composição - e esta é a razão pela qual lhe chamamos composto "aparente", uma vez que, embora a ordem mais comum seja [HOMEM $+\mathrm{N}$ ] ou [MULHER + N], a ordenação entre os sinais pode variar. (...) O fato de a ordem ser variável depõe contra a hipótese da composição, onde a ordem dos elementos componentes é invariável ${ }^{6}$. Além disso, a aposição dos

${ }^{5}$ Os gestos para os exemplos fornecidos pelas autoras encontram-se neste vídeo, que descobrimos ao longo da nossa pesquisa, nos minutos 2:24 e 2: 26. Disponível em: $<$ https://youtu.be/b6pmLU9mJTM>. Consultado em: 21 de junho de 2015.

${ }^{6}$ Como se mostra amplamente nos trabalhos de Rio-Torto (2013) e Rio-Torto (2014), não é o facto de a ordem dos constituintes ser variável nos compostos que invalida que o sejam. Não é habitual, mas podemos registar a ocorrência de médico-escritor 
sinais HOMEM ou MULHER na libras em geral não é obrigatória, pois é possível usar sinais como CRIANÇA, BEBÊ, JOVEM, IRM@ sozinhos na língua, sem qualquer referência ao sexo do referente. (...) (SILVA e SELL, 2009, s.p., consultado em 15 de junho, 2015)

Outros estudos sobre a LIBRAS, como o de Felipe (2006), apresentam conclusões semelhantes, porém não distinguem a formação de género de outros processos de composição morfológica, considerandoos “justaposição de dois itens lexicais, ou seja, dois sinais que formam uma terceira forma livre como, por exemplo, nos sinais (...) MULHER^BEIJONA-MÃO = mãe" (FELIPE, 2006, p. 207). A autora parece, também, considerar flexão para género (sic) como um dos cinco mecanismos de modificação interna da raiz que "marcando a concordância de género (animado-pessoa, animal e inanimado- coisa e veículo), através de configuração de mão específicas, funciona como classificadores" (FELIPE, 2006, p. 204). A linguista não fornece exemplos de gestos que ilustrem esta afirmação, e parece haver alguma hesitação entre considerar a marcação do feminino enquanto um processo de composição ou como uma forma que se socorre de unidades específicas, os classificadores, que são, relembramos, unidades morfémicas com significado gramatical e alto grau de iconicidade que reproduzem, metonimicamente, características visuais ou semânticas dos referentes, como a forma e o tamanho. Não conhecemos nenhum exemplo de formação de género com recurso a classificadores na LIBRAS, nem encontrámos nenhum item ao longo da nossa pesquisa. Além disso, o gesto de MÃE que a autora apresenta para ilustrar o feminino pode, em si, conter um classificador, mais concretamente o de "beijo na mão" que retém um significado atribuído numa época e em algumas culturas à figura da "mãe" e do "pai". Todavia,

e escritor-médico. Quando os compostos são Nome+Nome geralmente a ordem não varia, mas Adjetivo+Nome e Nome+Adjetivo pode oscilar o lugar ocupado por cada um dos constituintes e, neste caso, MACHO e FÊMEA são nomes com função apositivo-modificativa. 
no nosso entender, não é esse o gesto marca de feminino, pois ele também está presente no gesto de pai, sendo que aquilo que os distingue é o uso de "HOMEM" ou "MULHER"7.

Em suma, as investigações sobre o género na LIBRAS seguem, então, este rumo: a marcação de género faz-se por composição, notandose alguma hesitação na classificação do processo. O que parece ser seguro é o facto de a marcação de género ser contextual, e não obrigatória, facto que apenas se observa em contexto frásico ou de situação.

Antes de nos dedicarmos à Língua Gestual Portuguesa, procurando ver se é possível afinar mais a classificação da marcação de género com o processo de composição ou, então, propor nova hipótese, atentemos no que se passa em outras línguas gestuais que não a LIBRAS ou a ASL, que foram objeto de estudo dos trabalhamos que citámos.

Socorrendo-nos de uma ferramenta disponível online, que já indicámos em nota, o spread the sign, que permite observar como se executa em diversas línguas gestuais o mesmo conceito, observámos o seguinte na marcação de género.

Há quatro tipos de marcação de género:

1. Com a anteposição de um gesto muito semelhante àquele que é usado para designar MULHER antes do nome ${ }^{8}$;

2. Usando um gesto muito semelhante ou idêntico àquele que é usado para designar MULHER depois do nome;

\footnotetext{
7 Os exemplos podem consultar-se neste vídeo aos minutos 00.29 e 00:32 < https:// youtu.be/b6pmLU9mJTM>.

8 Consulte-se os exemplos para "irmã” disponíveis no spreadthesign, mais concretamente nas línguas gestuais dos seguintes países: Brasil; Turco; Checo; India; Polónia. De notar que o gestuante está condicionado o que pode significar, como adiante veremos para a LGP, que a marca do feminino nem sempre ocupa a mesma posição em contexto. In: $<$ www.spreadthesign.com>.

9 Veja-se o mesmo exemplo, "irmã", disponível no spreadthesign na língua gestual castelhana. De novo chamamos a atenção para o facto de o informante estar condicionado. In: <www.spreadthesign.com>.
} 
3. Há gestos distintos para designar masculino e feminino ${ }^{10}$;

4. Não há marcação de género ${ }^{11}$.

Tratando-se de um dicionário que funciona por busca de palavra e não oferece exemplos contextuais, não nos é possível verificar noutras línguas gestuais se a marca de género é obrigatória ou situacional, como foi sugerido pelas investigadoras brasileiras que acima citámos. Além disso, tratando-se de exemplos gestuados por condicionamento do informante, a quem foi pedido um vocábulo isolado, não é verificável se alguns dos gestos descritos em 1) e 2) perdem propriedades indiciando "justaposição". Porém, cremos, há algo a acrescentar ao que temos vindo a rastrear sobre a investigação do género em línguas gestuais. Os nomes são marcados segundo dois processos diferentes, sendo que os referidos em 1) e 2) só serão passíveis de se delimitar gramaticalmente quando observada a língua em contexto. Já o referido em 3) parece ser mais simples, pois ilustra um processo de variação lexical do tipo que se encontra, também, em línguas orais, como se verifica para o português. Os exemplos mencionados em 4), sendo isolados, repetimos, não nos fornecem indicação de como se comportam em contexto frásico, isto é, não é possível saber se num caso em que o gestuante precisasse de distinguir o sexo do parente, no caso do exemplo escolhido, ou do animal, não se serviria do gesto que designa MULHER naquelas línguas gestuais ou de um outro processo. Todavia, há que ter em conta que muitas línguas gestuais, das quais a LGP não é exemplo, possuem na constituição dos gestos o designado mouthing. Este recurso, presente em muitas línguas gestuais

\footnotetext{
${ }^{10}$ Mantenha-se o mesmo item de pesquisa, "irmã" e veja-se como ocorre nas línguas gestuais dos seguintes países: Itália, Estados Unidos da América, França, Japão, Inglaterra, Bulgária, Ucrânia, Letónia e Rússia.

${ }^{11}$ Continuando a pesquisar o vocábulo "irmã" verificamos que é idêntico ao de "irmão" nas línguas gestuais de Alemanha, Lituânia, Suécia, Roménia, Áustria e Islândia. Como veremos mais à frente, este fenómeno poderá encontrar explicação no mouthing, a que aludimos no corpo do texto.
} 
europeias (SANDLER e LILLO MARTIN, 2006, p. 104), consiste na labialização de uma palavra ou de parte de uma palavra da língua oral que é constituinte do gesto. Todavia,

it would be a mistake to interpret mouthing as speech accompanying sign (...) though borrowed from the spoken language, appears to perform sign-language-internalfunctions. (...) mouthing [can] disambiguate two otherwise similar sign, in this way performing a significant lexical role (Sandler e LILLO MARTIN, 2006, p. 104).

Desta forma, uma maneira de marcar o feminino, nas línguas gestuais em apreço, pelo menos contextualmente, poderá ser a labialização da palavra ou de parte dela que, na língua oral, distingue o feminino do masculino.

Por último, cremos que a marcação de género em várias línguas gestuais segue processos muito semelhantes, como ocorre, aliás, em línguas orais de raiz comum ${ }^{12}$. Os estudos sobre cultura e poesia surdas (KARNOPP, 2010) tem vindo a demonstrar que a comunidade surda, especificamente aquela que utiliza uma língua gestual para expressar o mundo, une-se com temáticas de cariz semelhante, que a identificam, como a opressão ou o orgulho numa língua gestual, tendo, por isso, manifestações poéticas com características afins. Cremos que algo parecido se passa com a formação das línguas gestuais. É evidente que as línguas gestuais têm línguas mães distintas, sendo, também por isso, formalmente diferentes. Todavia, a criação de gestos puros é motivada, num primeiro grau, pela iconicidade. Talvez por isso os processos de marcação de género, e outros que veremos mais à frente, se concretizem de maneira muito idêntica, ou seja, grande parte das línguas gestuais têm processos de formação e de organização muito comuns. Contudo, sendo os processos os mesmos, eles não são paralelos; como vimos, uma mesma palavra pode ter marcação

${ }^{12}$ Veja-se, entre muitos exemplos, o que acontece nas línguas românicas como francês ou castelhano em que há marcação de género recorrendo ao uso de artigo definido ou à adição de morfema sufixal ou de tema: le chien/la chienne; el perro/la perra. 
de feminino por um gesto anteposto e, noutra língua, essa marcação será lexical. Há que atentar na especificidade diacrónica e na evolução de cada língua para compreender como, também cultural e historicamente, se materializam estes processos. Vejamos, de seguida, a LGP, procurando validar as sugestões que apresentámos.

\section{O género na Língua Gestual Portuguesa: delimitar fronteiras}

Como já dissemos, não abundam os estudos dedicados à linguística da Língua Gestual Portuguesa. Assim, apenas podemos referir dois trabalhos, de índole diversa, que dedicam algumas linhas à questão do género. O primeiro remonta a 1994 e tem propósitos claramente didácticos, pois trata-se de uma proposta de uma gramática da LGP. Nas cinco páginas relativas ao género, ilustrado com exemplos da LGP fotografados, retemos o seguinte (AMARAL \& COUTINHO, 1994, p. 83-88):

- o género na LGP é marcado ou não marcado podendo não possuir "qualquer marca nem de masculino nem de feminino" (p. 83);

- só quando é necessário explicitar o sexo dos seres animados é que pode ocorrer marcação de género (p. 83);

- para os seres humanos existe um gesto próprio que designa homem e outro mulher (p. 83);

- na marcação de sexo em humanos aplicam-se estas marcas, em norma, por prefixação mas também pode ocorrer sufixação (p. 84);

- os nomes marcados comportam-se como gestos compostos;

- além das formas que acima listámos, "consideradas regulares" (p. 87) há utilização de "gestos diferentes para o masculino e para o feminino" (p. 87). 
Antes de atentarmos nas propostas acima listadas, vejamos o que nos diz um estudo mais recente de natureza comparatista entre a LIBRAS e a LGP na secção 3, dedicada a aspectos gramaticais (BARBOSA e RAFAEL, 2014, p. 24-25):

\begin{abstract}
$\mathrm{Na}$ Libras, a flexão de gênero não ocorre em substantivos, adjetivos e pronomes, e, em caso de seres animados, a marcação do sexo se dá pela sinalização [HOMEM]/ [MULHER] seguido do sinal principal, tanto para pessoas quanto para animais (BERNARDINO, 1999; QUADROS e KARNOPP, 2004). Há apenas alguns sinais referentes a masculino/feminino que são diferentes em algum parâmetro, como o par [CARNEIRO]/[OVELHA], em que a configuração de mão é o diferenciador. Já na LGP a concordância de gênero se dá através de gestos diferentes ([PAI/[MÃE]) e através da marcação do feminino por prefixação $([$ RAPARIGA $]=[$ MULHER $]+[$ RAPAZ $])$ - ao contrário da Libras, que marca os dois sexos. Em alguns casos, o gênero na LGP é marcado pelo referente dêitico (caso de [NAMORADA] + [MINHA], em que normalmente não se faz necessário marcar que é uma mulher, se o referente for um homem, e vice-versa) e por sufixação $([\mathrm{BODE}]=[\mathrm{CABRA}]+[\mathrm{BARBICHA}])$. Os seres inanimados não apresentam marcação de gênero nessa língua (MESQUITA e SILVA, 2009).
\end{abstract}

Como se verifica, o estudo comparatista que citámos pouco acrescenta ao de 1994. Além disso, possui algumas imprecisões nos exemplos fornecidos para LGP, nomeadamente aquele que se refere à sufixação no par CABRA/BODE. Como se verifica no dicionário online que temos usado, bem como consultas efetuadas a diversos gestuantes nativos e proficientes da LGP, este par é realizado com recurso a gestos diferentes. O recurso a fontes escritas que reproduzem a LGP sem utilizar exemplos de gestuantes nativos e fluentes na língua, pode trazer equívocos. Todavia, o que importa reter é quais os processos que estes estudos consideram para a formação de género na LGP. Assim, constata-se que se refere o uso de gestos diferentes, a não marcação de 
género ou a marcação contextual, e a prefixação e a sufixação quando o género é marcado. Vejamos estas sugestões mais de perto.

\section{LGP: Masculino Feminino e Neutro- Natural Gender System}

Em primeiro lugar, concordamos com Amaral e Coutinho (1994), pois, na LGP, o género apenas pode ser marcado em seres animados, sendo, às vezes, como adiante veremos, omitido. Assim, sugerimos que, para a LGP, se considere uma tripartição de género: masculino, feminino e, para os seres inanimados, neutro. Consideramos interessante adotar a terminologia proposta por Corbett (1991) para a formação de género em línguas que se servem de traços semânticos dos seres animados para os distinguir, isto é, a LGP poderá ter um sistema natural de marcação de género ("natural gender systems"). Também se observa que o masculino, na maioria dos casos, é não-marcado e, quando é, serve apenas para clarificar a mensagem.

\section{LGP: Marcação de Feminino por Variação lexical}

Em segundo lugar, é notório o "uso de gestos diferentes" para distinguir o masculino e o feminino, mas não só como parece indiciar o trabalho de Amaral e Coutinho (1994) no campo semântico restrito aos animais: a variação lexical pode igualmente ocorrer no campo semântico dos seres humanos, das profissões e da família. Dessa forma, podemos afirmar que, à semelhança do que se passa em outras línguas gestuais, e também nas línguas orais, a variação lexical é um dos processos de marcação de género na LGP. Essa variação lexical consiste, na esmagadora 
maioria dos $\operatorname{casos}^{13}$, no uso da metonímia ${ }^{14}$ para formar a palavra. Assim, veja-se, por exemplo, OVELHA/CARNEIRO em que o formato e a extensão dos chifres do animal designam o referente completo, e também idêntico, processo no par GALO/GALINHA em que o lugar das cristas das aves são os parâmetros distintivos de género ${ }^{15}$.

Para além do uso da metonímia, destaca-se igualmente a utilização da metáfora ${ }^{16}$, e os gestos refletem uma interpretação cultural. Assim, em PAI, o gesto é executado na zona do bigode, característica associada a masculino, e MÃE realiza-se abaixo do queixo demonstrando a evolução de um comportamento cultural antigo que era o de beijar a mão da mãe pedindo a bênção ${ }^{17}$.

Por último, no que à variação lexical diz respeito, veja-se o exemplo de ENFERMEIRO/ENFERMEIRA ${ }^{18}$, que combinam, a nosso ver, um processo de marcação de género com recurso à metonímia e à metáfora. Esse par tem origem no histórico e característico chapéu das enfermeiras - que tinha uma cruz vermelha -, artefacto que não era usado pelos enfermeiros, pois seria no braço que tinham a cruz. Apesar de a variação ser mínima nesse par, cremos estar perante uma variedade lexical, pela raiz

${ }^{13}$ Consulte-se, www.spreadthesign.com para, por exemplo, os pares cabra/bode; boi/ vaca; galo/galinha.

${ }^{14}$ Entenda-se por metonímia "um mecanismo semântico que consiste em denominar uma entidade A por meio da denominação de uma entidade $B$, sendo que $A{ }^{1} \mathrm{~B}$, mas ambas as entidades mantêm entre si uma relação de contiguidade (de conteúdo a continente, de parte a todo, de matéria a produto etc.)" (CORREIA, 2000, p. 12).

${ }^{15}$ Os exemplos estão disponíveis em: <www.spreadthesign.com>.

${ }^{16}$ Retenha-se o que é dito sobre nomeação metafórica: "na nomeação metafórica, por sua vez, o objeto é denominado não por características objetivas, mas por conta de propriedades transferidas em termos associativos. Em louva-a-deus, por exemplo, a postura do inseto lembra alguém em oração".(SILVA, 2011). Disponível em: < http:// www.scielo.br/scielo.php?script=sci_arttext\&pid=S1984-63982011000100003 >. Consultado em 13 de jun. de 2015.

${ }^{17}$ InformaçãoCedidaporgestuantesnativosdacomunidadesurda.Veja-se,também, “Análise Diacrónica em Língua Gestual Portuguesa: o caso da família” (PEREIRA). Disponível em: $<$ http: / www.porsinal.pt/index.php?ps=artigos\&idt=artc\&cat=9\&idart=270>. Os vídeos estão disponíveis em: <www.spreadthesign.com>.

${ }^{18}$ Exemplos disponíveis em: <www.spreadthesign.com>. 
cultural que a motivou, mas, também e sobretudo, porque não há qualquer gesto anteposto ou sucessivo que marque o feminino.

\section{LGP: Marcação de género por composição?}

Em terceiro e último lugar, observemos a questão que, de acordo com a bibliografia consultada e citada, parecer ter respostas menos simples. Como vimos, trabalhos sobre a LGP e outras línguas, mais concretamente a LIBRAS, mostram algumas hesitações, terminológicas e outras, quanto à marcação de género por prefixação, sufixação ou composição.

Numa primeira análise, diríamos que se trata de um processo por composição, semelhante ao que se observa em português para os nomes epicenos, uma vez que se trata de gestuar o nome MULHER, seguindo-se o gesto do referente que se pretende marcar. Este novo gesto teria comportamentos típicos que os compostos têm nas línguas gestuais e na LGP em particular, pois ocorre a "presença de um traço de suspensão-contacto em qualquer dos gestos" (AMARAL e COUTINHO, 1994, p. 113). Assim, um dos itens do composto perderia um dos queremas que o caraterizam na sua forma original, ou então esse querema seria reduzido, ou seja, poderia perder movimento, mudança de configuração ou expressão não-manual (ENM). Assim, o gesto MULHER teria um movimento de deslize pelo rosto menor e/ ou perderia a componente não manual que consiste em colocar a língua no interior da bochecha. Como se observa na língua em uso, muitas vezes o gesto MULHER não tem a componente ENM, podendo esta estar a perder-se, naturalmente, devido à velocidade de enunciação da língua. Aliás, o mesmo informante que gestuou o exemplo em feminino, nessa ocasião, retira-lhe a componente ENM; porém, quando lhe solicitámos 
que gestuasse os vocábulos, não o fez. Desta forma, não parece ser uma perda de um traço motivada pela composição ${ }^{19}$.

Poder-se-ia, então, concluir que se trata de composição morfossintática, estando ambos os componentes íntegros. Não deixa de ser uma hipótese válida, mas isso nem sempre acontece, e, observando o uso da LGP em contexto, verifica-se que os gestuantes distinguem semanticamente os dois "conceitos", isto é, ao marcar o género de uma palavra, o gestuante não lhe associa os traços semânticos de MULHER, sobretudo o traço [+humano], mas sim de feminino. Assim, se compreende que a marcação de género no animal GATA seja a mesma que em ARQUITETA. Para além disso, não estamos perante "uma palavra composta que representa um significado único e autónomo, muitas vezes dissociado das noções expressas pelos seus componentes" (AMARAL e COUTINHO, 1994, p. 113).

Essa hesitação leva-nos a propor uma outra hipótese: será que o constituinte que marca o género em LGP estará numa fase de transição entre "o estatuto de bases e o de afixos" (GRAMÁTICA DERIVACIONAL DO PORTUGUÊS, 2013, p. 95)? Estes constituintes têm as seguintes características, segundo a Gramática Derivacional do Português (2013, p. 95):

a) Produtividade crescente;

b) Diminuição da especificidade semântica;

c) Relação etimológica e formal com uma base.

Cremos que a marcação de género em LGP com recurso a um constituinte que terá derivado da base MULHER, transformandose num "afixo de informação gramatical”, encaixa na definição acima $\operatorname{citada}^{20}$. Dessa forma, estamos perante um processo de transição em

${ }^{19}$ A figura ilustrativa desta nuance pode ser consultada na tabela-síntese do género que apresentamos em anexo.

${ }^{20}$ Talvez a "produtividade crescente" seja mais difícil de considerar neste caso, uma vez que nos reportamos à informação gramatical, e não semântica. 
que a marca de feminino perde a informação lexical da base de onde proveio, sendo apenas um recurso distintivo. Porém, se continuarmos a ler a definição destes "afixóides", outro problema se levanta: "o afixo não admite alteração na sua posição em relação à base" (GRAMÁTICA DERIVACIONAL DO PORTUGUÊS, 2013, p. 96). Ora, os exemplos observados mostram-nos que nem sempre é assim. Na realidade, na maioria das vezes o género é marcado antes do gesto, mas pode ser marcado a seguir. No momento, o que se observa é um estado de transição entre um composto-semi-composto e um afixo, que se resolverá, certamente, com o uso e com mecanismos de regulamentação ainda inexistentes como gramáticas e dicionários.

\section{LGP: Concordância e Obrigatoriedade de Género}

Em Língua Gestual Portuguesa, o género feminino nem sempre é marcado. Quando os referentes são facilmente identificáveis não há necessidade de marcar o género, apenas será caso disso se for preciso desambiguar. Por exemplo, se um homem falar da sua namorada, não marca o género nesta palavra, mas noutros contextos ela pode ser marcada, por exemplo, caso trate-se de uma relação homossexual. O processo de oscilação do lugar dos constituintes verifica-se, também, noutros contextos, parecendo ser um processo querológico ${ }^{21}$ que assume variações consoante o gesto que o segue ou precede. A falta de uma gramática que sintetize as ocorrências e, de alguma forma, sistematize as regras a usar, estará, certamente, na causa dessa hesitação.

Um segundo aspeto importante a considerar é que em LGP não há concordância entre o nome e o adjectivo que nunca apresenta marca de género. Essas particularidades, a não obrigatoriedade de marcação de

${ }^{21}$ Por exemplo, o gesto ALMOÇAR pode gestuado com TARDE+VERBO ASPETUAL ou verbo ASPETUAL+TARDE. Veja-se a primeira opção em: <www.spreadthesign.com>. 
género e a não concordância, são facilmente compreendidas, pois trata-se de uma língua de modalidade visual. Quando o contexto é suficiente, quando não há a necessidade de especificar, a LGP segue o universal princípio da economia linguística. Contudo, retenha-se que no ensino formal da LGP a marcação de género é explícita considerando-se a variação lexical de que acima falámos, e a marcação com recurso a "esta marca de feminino" antes do gesto que se pretende diferenciar. Assim, talvez este "afixo" se venha a cristalizar quando houver instrumentos reguladores que assim o propiciem.

\section{O Género e o ensino Bilingue: algumas propostas}

Após termos descrito a concretização do feminino em LGP, propomos algumas sugestões que intentam unir a descrição linguística com o ensino da língua. Em primeiro lugar, e como o Programa Curricular de Língua Gestual Portuguesa (2007) advoga, é fundamental que o domínio do estudo da língua seja sistematizado, para que o aluno possa refletir nas regras naturais do seu idioma. O professor de LGP deve promover exercícios que, no que concerne o tema deste nosso artigo, levem os alunos surdos a perceber como se marca o género. Se esta sistematização for levada a cabo na língua natural do aluno surdo, então, cremos, pode ser menos penoso o ensino de uma língua oral em que o género tem outras particularidades, o português.

É sabida a importância da imagem no ensino bilingue de alunos surdos, e é prática a associação gesto/imagem/palavra logo desde o préescolar. Esta estratégia, que visa o enriquecimento vocabular nas duas línguas e a aquisição de conceitos, pode também ser usada para estimular a emergência das regras gramaticais na segunda língua do surdo.

No que concerne o contraste de género, como sabemos, em português ele ocorre pela variação temática em- a para a marcação do feminino e/ou pela anteposição de artigo definido a/o antes do nome 
e do adjetivo ${ }^{22}$. Este processo é diferente daquele que acima analisámos para a LGP. Assim, parece-nos fundamental que, para além da palavra a legendar a imagem, se inclua o artigo definido que marca, também, o género do nome. Não é nosso intuito que a criança em idade pré-escolar sistematize esta regra, porém, o surdo é um ser eminentemente visual, e o facto de ser exposto a este processo fará com que, ainda que de forma implícita, reconheça a necessidade de antepor o artigo antes do nome na sua segunda língua (L2).

Para além de estimular a emergência de uma gramática de L2 com a sugestão acima, cremos que o segundo passo, já no ensino formal, passa por sistematizar as regras de formação de género nas duas línguas. Como já afirmámos em outra publicação (CORREIA, 2012), o professor do $1^{\circ}$ ciclo do ensino básico e o professor de português de qualquer ciclo de ensino de alunos surdos deve conhecer a estrutura da LGP. Sendo o português uma língua opaca, ou seja, em que não há uma relação direta entre o fonema e o grafema, eminentemente fonológica, supomos que a sua aprendizagem efetiva só pode ocorrer com recurso ao contraste e/ou à sistematização através da LGP.

Como vimos, o feminino em Língua Gestual Portuguesa é marcado pela anteposição, na maioria dos casos, de um gesto antes do ser animado que se pretende marcar. Em português, ao invés de uma palavra anteposta recorre-se ao artigo e à mudança de tema. Cremos que se o aluno entender este processo nas suas semelhanças e diferenças lhe será mais fácil

${ }^{22}$ A não-obrigatoriedade de existência de contrastes de género e o facto de a sua realização estar a cargo quer de processos estritamente lexicais, pelo contraste de índices temáticos (cf. aluno/aluna; professor/professora) ou pelo contraste de diferentes palavras (cf. homem/mulher, carneiro/ovelha), quer de diversos processos morfológicos como a derivação (cf. barão/baronesa; judeu/judia; europeu/europeia; conde/condessa; lavrador/lavradeira; imperador/imperatriz; espertalhão/espertalhona) e a composição (cf. águia-macho/águia-fêmea), são propriedades que distinguem claramente o género das restantes categorias morfo-sintácticas disponíveis no português, e que justificam a sua análise como uma categoria não-flexional (...) Os tradicionalmente chamados "morfemas de género" dos adjectivos e nomes do português não têm qualquer relação com o género (nem com a flexão), mas sim com a classe temática a que cada palavra pertence (GRAMÁTICA DA LÍNGUA PORTUGUESA, 2001, p. 930-931) 
compreender a regra do feminino em português. Há que acrescentar que a LGP apenas marca seres animados, isto é, como afirmámos, há muitos gestos neutros algo que não ocorre em português. Neste caso, a estratégia didática poderá passar por afirmar que em português tudo é marcado e poderá também ser interessante, a partir do terceiro ciclo, exemplificar que a língua inglesa também possui o neutro no que respeita ao género. Para além disso, pode ser útil explicar que em português a marcação de género de várias espécies animais também se faz com recurso a macho/fêmea, ou seja, a marcação sucede o nome do animal, e em LGP precede. A aprendizagem por contraste constitui-se como significativa para o aluno, pois o professor recorre à sistematização da língua natural do aprendente, e que este conhece pelas aulas de LGP, para lhe ensinar uma língua segunda. Assim, há a valorização da identidade surda do aluno e o reforço positivo que o pode levar a perceber que o caminho para o bom domínio do português não tem de ser árduo e estéril.

Por último, a formação de feminino por variação lexical também ocorre em português. O professor pode recorrer a uma tabela que ilustre quais são os femininos por variação lexical em LGP e em português. $O$ aluno verá que alguns coincidem, como por exemplo, o caso de cabra/ bode, mas outros divergem, como cavalo/égua, que é lexical em português e não em LGP. Para concretizar a sistematização da regra e seus contrastes, podemos criar a Roleta do Género. Através de uma roleta em cartão ou outro qualquer material em que haja desenhos de vários animais, profissões, graus de parentesco, o aluno terá de lançar o dado e depois dizer como se marca o feminino da imagem. Por exemplo, imaginemos que calhou na imagem de um cão. Então, enquanto que em LGP será marcado através de MULHER+CÃO, em português a variação é lexical, sendo o correto cadela. Esta roleta pode incluir imagens que em LGP serão de género neutro e em português marcado, ou outras materializações de género que acima descrevemos, sendo o objetivo a sistematização dos processos de feminino em português, partindo do conhecimento explícito 
que a criança possui da sua língua. $\mathrm{O}$ aluno deve escrever uma lista para poder memorizar e estudar, mas, o fundamental, é perceber o processo aplicando-o em frases e textos.

Em conclusão, a descrição efetiva da LGP contribui decisivamente não apenas para o registo da língua, mas sobretudo para o conhecimento explícito em seu torno.

A perspetiva descritiva foi aquela que assumimos pois os estudos são escassos e, cremos, um dos primeiros passos é observar e sistematizar os processos gramaticais intrínsecos da língua. Em contexto de ensino formal, a descrição do género em LGP que apresentámos pode contribuir para tornar a aprendizagem da lecto-escrita mais significativa e sólida.

\section{Agradecimentos}

Agradeço à professora Graça Rio-Torto todo o acompanhamento e sugestões pertinentes quando da realização do meu pós doutoramento. O meu nunca suficiente obrigada ao Amílcar Furtado o informante nativo que deslindou muitas das minhas dúvidas.

\section{Referências}

AMARAL, M. A.; COUTINHO, A.; DELGADO MARTINS, M. R. Para
Uma Gramática da Língua Gestual Portuguesa. Lisboa: Caminho, 1994.

BARBOSA, E.; RAFAEL, F. Breve Estudo Comparativo Entre a Língua Gestual Portuguesa (LGP) e a Lìngua Brasileira de Sinais (LIBRAS): Implicações de Duas Línguas Espaço-Visuais Diferentes em Países que Falam a Mesma Língua Oral Oficial. Centro Virtual de Cultura Surda, Revista Virtual de Cultura Surda, no 12, janeiro, 2014, Arara Azul. 
Disponível em: <http://editora-araraazul.com.br/site/admin/ckfinder/ userfiles / files $/ 1 \% \mathrm{C} 3 \% 82 \% \mathrm{C} 2 \% \mathrm{BA} \% 20$ Artigo $\% 20 \mathrm{da} \% 20$ Revista $\% 20$ 12\%20\%5BBARBOSA\%20\%26\%20RAFAEL $\% 5$ D.pdf $>$. Consultado em: set. 2016.

CAVACA, F. (Coord), Programa Curricular de Língua gestual Portuguesa Para o Ensino Básico, Ministério da Educação, DGDIC, 2007. Disponível em: <http://www.dge.mec.pt/sites/default/files/ EEspecial/doc_programa_curricular_lgp_basico.pdf $>$.

CORBETT, G., Gender. Cambridge: Cambridge University Press, 1991.

CORREIA, I. Entre Línguas se (Des)constrói um texto. Interferência Linguística da LGP no Português. EXEDRA, Revista Científica da Escola Superior de Educação de Coimbra, número temático, Investigação e Ensino, p. 52-66, 2012. Disponível em: <http://www.exedrajournal. com/?p=154>. Consultado em: 26 abr. 2015.

CORREIA, M. Homonímia e Polissemia. Contributos para a delimitação de Conceitos, Palavras, $n^{\circ} 19$, Associação dos Professores de Português, pp.55-75, s.d. Disponível em: < http://www.iltec.pt/pdf/ wpapers/2000-mcorreia-homonimia_polissemia.pdf $>$. Consultado em: nov. 2016.

FELIPE, T. Os Processos de Formação de palavra na Libras. Educação Temática e Digital, Campinas, v. 7, nº 2, jun. 2006, p. 200-217. Disponível em: $\quad<$ http://periodicos.sbu.unicamp.br/ojs/index.php/etd/article/ view/803>. Consultado em: 22 jun. 2015.

FELIPE, T. Sistema de Flexão Verbal na LIBRAS: os classificadores enquanto marcadores da flexão de género. Anais do Congresso de Surdez 
e Pós-Modernidade: Novos Rumos para a Educação Brasileira $1^{\circ}$ Congresso Internacional do INES. $7^{\circ}$ Seminário Nacional do INES, Rio de Janeiro, INES, 2002, p. 37-58. Disponível em: <http://www. institutoconscienciago.com.br/pdf/aee/ClassifemLIBRASINES2002. pdf>. Consultado em: 23 jun. 2015.

FIGUEIREDO SILVA, M. C.; SELL, F. F. S. Algumas notas sobre os compostos em português brasileiro e em LIBRAS, 2009. Disponível em: <http://linguistica.fflch.usp.br/sites/linguistica.fflch.usp.br/files/ FIGUEIREDOSILVA-SELL.pdf>. Consultado em: 26 jun. 2015.

KARNOPP, L. B. Produções culturais de surdos: análise da literatura surda. Cadernos de Educação (UFPel), ano 19, p. 155-174, 2010.

MATEUS, M. H. et al. Gramática da Língua Portuguesa. Lisboa: Caminho, 2001.

QUADROS, R, M.; KARNOPP, L. B. Língua de Sinais Brasileira. Estudos Linguísticos. São Paulo, Artmed, 2004.

PEREIRA, J. Análise Diacrónica em Língua Gestual Portuguesa: o caso da família. Disponível em: <http://www.porsinal.pt/index. php?ps $=$ artigos\&idt $=$ artc\&cat $=9 \&$ idart $=270>$.

RIO-TORTO, G. Nouns in apposition. Ana Maria Brito (org.), Linguística 8 (Conversion and mixed categories). Revista de Estudos Linguísticos da Universidade do Porto, p. 17-38, 2013.

. Prefixação e composição: fronteiras de um continuo. Verba 41 Anuario Galego de Filoloxía. USP, 2014 
RIO-TORTO, G. (Ed.); RODRIGUES, A.; PEREIRA, I. PEREIRA, R.; RIBEIRO, S. Gramática derivacional do português. Coimbra: Imprensa da Universidade de Coimbra, 2013.

SILVA, A. Metáfora e Metonímia: o traço-de-união entre os compostos, Revista Brasieleira de Linguística Aplicada, vol. 11, $\mathrm{n}^{\circ}$ 1, Belo Horizonte. Disponível em: <http://www.scielo.br/scielo.php?script=sci_ arttext\&pid=S1984-63982011000100003 $>$. Consultado em: 13 jun. 2015.

\section{Anexo}

Quadro Síntese da Codificação de Género em Língua Gestual Portuguesa

1 Masculino

2. Feminino

3. Masculino vs feminino

4. Neutro 


\begin{tabular}{|c|l|l|}
\hline Género & \multicolumn{1}{|c|}{ Processo } & \multicolumn{1}{|c|}{ Exemplos } \\
\hline \multirow{1}{*}{ 1. Masculino } & $\begin{array}{l}\text { Obrangente para o feminino e masculino quando } \\
\text { seres animados (e.g. o/ um amigo; fig.1), sendo } \\
\text { o género é descodificado pelo contexto; caso } \\
\text { contrário, é necessário marcar-se o feminino. } \\
\text { Não há concordância entre nome/adjetivo. }\end{array}$ & $\begin{array}{l}\text { 1-AMIGO. "Gesto bi-manual: configuração } \\
\text { de mãos em palma fechada, orientação de } \\
\text { mãos para o gestuante, os braços cruzam } \\
\text { sobre o peito, executa-se um movimento } \\
\text { da frente para trás, batendo no peito, duas } \\
\text { vezes". Vídeo disponível em: www. } \\
\text { spreadthesign.com }\end{array}$ \\
\hline
\end{tabular}




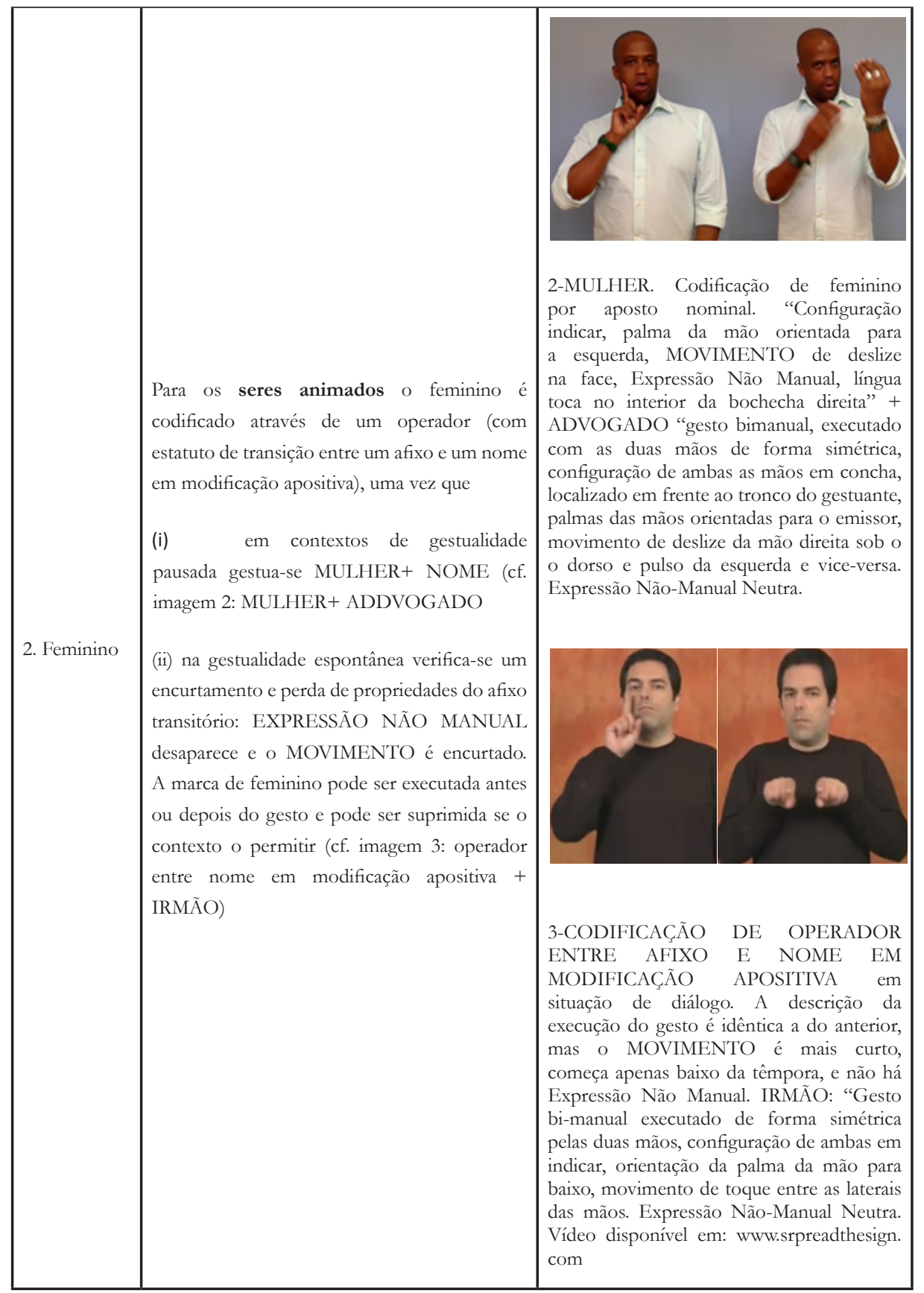




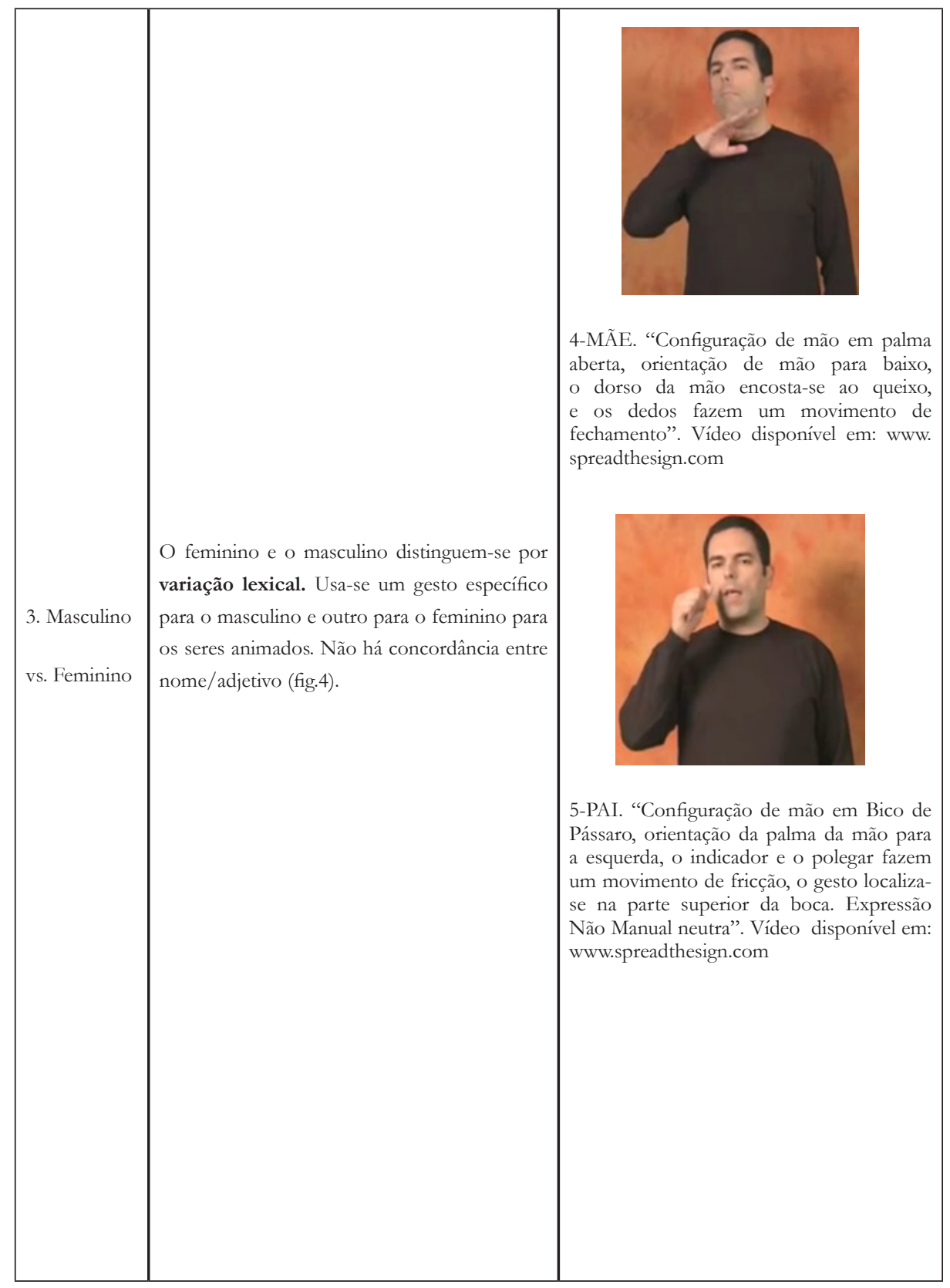




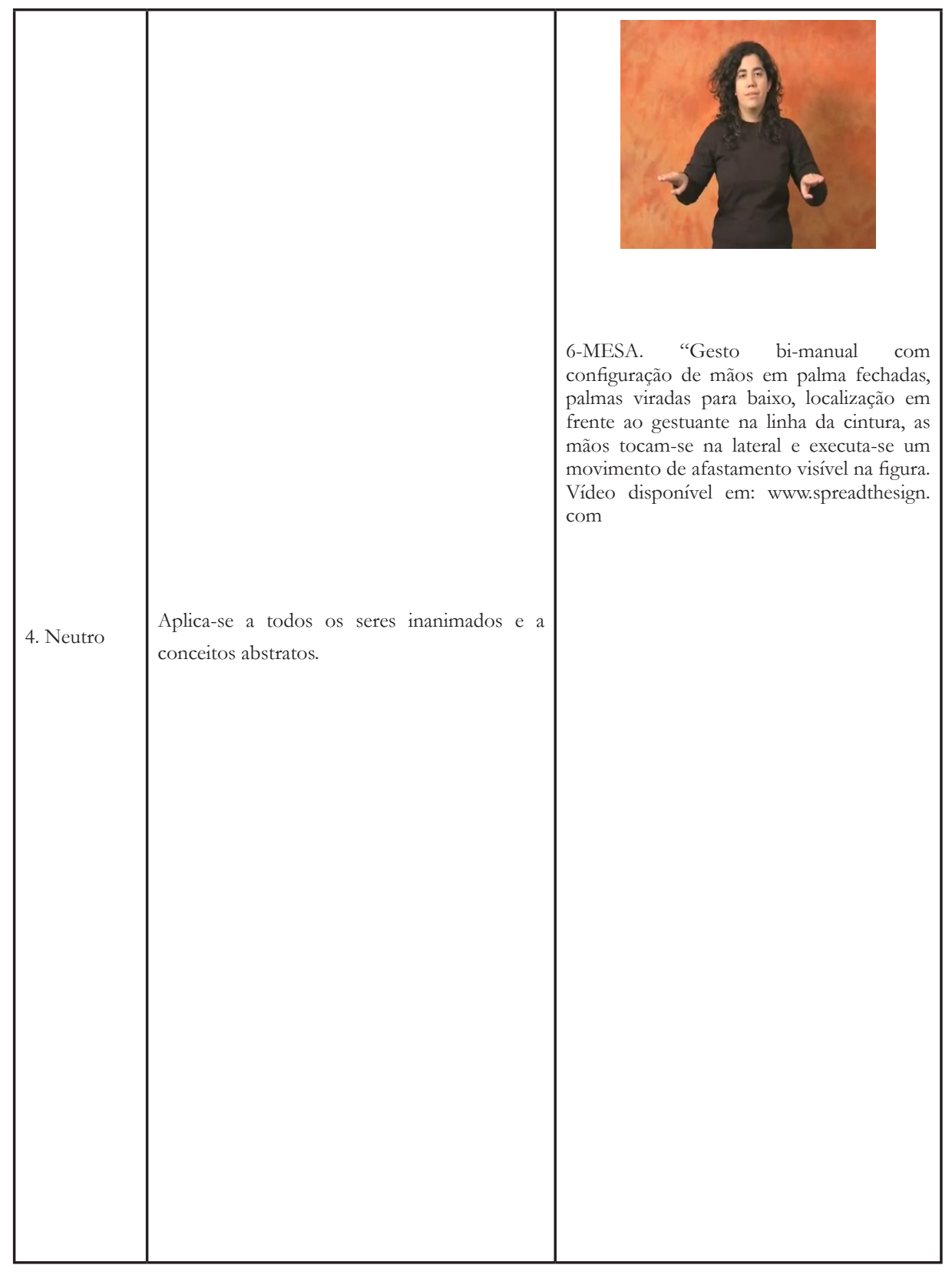

